\title{
No-touch Harvesting in Off-pump Coronary Artery Bypass Grafting With Sequential Saphenous Vein Graft: A Single-center Prospective Randomized Controlled Trial
}

\section{Xuejian Hou}

Beijing An Zhen Hospital: Capital Medical University Affiliated Anzhen Hospital https://orcid.org/00000003-4880-9055

\section{Kui Zhang}

Beijing An Zhen Hospital: Capital Medical University Affiliated Anzhen Hospital

Taoshuai Liu

Beijing An Zhen Hospital: Capital Medical University Affiliated Anzhen Hospital

\section{Yang Li}

Beijing An Zhen Hospital: Capital Medical University Affiliated Anzhen Hospital

\section{Yang Zhao}

Beijing An Zhen Hospital: Capital Medical University Affiliated Anzhen Hospital

\section{Bangrong Song}

Beijing An Zhen Hospital: Capital Medical University Affiliated Anzhen Hospital

\section{Zhuhui Huang}

Beijing An Zhen Hospital: Capital Medical University Affiliated Anzhen Hospital

\section{Shijun Xu}

Beijing An Zhen Hospital: Capital Medical University Affiliated Anzhen Hospital

\section{William Adiwignya Winata}

Beijing An Zhen Hospital: Capital Medical University Affiliated Anzhen Hospital Jubing Zheng

Beijing An Zhen Hospital: Capital Medical University Affiliated Anzhen Hospital

Ran Dong ( $\sim$ drdongran@126.com )

Department of Cardiac Surgery, Beijing Anzhen Hospital, Capital Medical University, Beijing, China https://orcid.org/0000-0002-1488-5423

\section{Research article}

Keywords: Coronary artery bypass grafting(CABG), No-touch saphenous vein graft harvesting, off-pump $C A B G$, sequential saphenous vein grafting, Conventional saphenous vein graft harvesting 
Posted Date: September 23rd, 2020

DOl: https://doi.org/10.21203/rs.3.rs-78252/v1

License: (c) (i) This work is licensed under a Creative Commons Attribution 4.0 International License. Read Full License 


\section{Abstract}

Background: Coronary artery bypass grafting (CABG) materials comprise the combination of the left internal mammary artery and saphenous vein. The patency rate of vein grafts is considered not ideal; more studies support that the no-touch (NT) procedure can improve the patency rate of vein grafts. However, it is not clear that the NT technology is used in the sequential saphenous vein grafting during off-pump coronary artery bypass surgery. This study explored whether the NT technique is safety and efficacy compared to the conventional manner in the off-pump coronary artery bypass surgery using sequential vein graft.

Methods: This was a prospective single-center randomized controlled clinical trial. A total of 200 patients undergoing off-pump coronary artery bypass grafting in the sequential saphenous graft were randomly assigned to two groups: The no-touch(NT) and the conventional (CON) groups. Perioperative and postoperative data were collected prospectively during the hospital stay. The occlusion of sequential grafts was measured by cardiac computed tomography angiography (CCTA) 3-months post CABG. Leg wound complications were followed up. The mean diameter of sequential grafts for the first 100 patients was measured using CCTA, 3-months after the operation.

Results: The primary endpoint was that there was no difference in occlusion of sequential venous grafts between the two groups (NT: 9/180 (4.4\%), CON: 5/194 (1.5\%), $p=0.22)$. Similarly, there were no differences in composite clinical events (NT: 2/91 (2.2\%), CON: 1/96 (1.0\%), $p=0.96)$. There was no difference in the leg wound complications between the two groups (NT: 8/91 (8.8\%), CON: 4/96 (4.2\%), $p=0.20)$. However, there was a significant difference in the average diameter of sequential grafts between the two groups (NT: $(2.98 \pm 0.42), \mathrm{CON}:(3.26 \pm 0.51), p=0.005)$.

Conclusions: The early clinical results suggest that the NT technique is safety and efficacy compared to the conventional technique in sequential grafting in off-pump coronary artery bypass surgery. The sequential grafts early expansion in the NT technique is not as pronounced as the conventional technique, which may have a long-term protective effect on the grafts.

Trial Registration: Registered 1 November 2018, ClinicalTrials.gov NCT03729531, http://www.clinicaltrials.gov

\section{Introduction}

Coronary artery disease remains one of the major serious diseases that threaten human health. Coronary artery bypass surgery is an effective way to handle the multi-vessel disease, complex lesions, and severe left main coronary heart disease [1-3]. The graft materials are mainly the combination of the left internal mammary artery and saphenous vein (SV) [4]. Early graft failure after CABG was present in up to $12 \%$ of grafts [5]. The internal mammary artery is the gold graft [6]. However, the low patency rate of the saphenous vein remains a big challenge [7]. One month after the operation, the main factor affecting the venous patency rate was the formation of acute thrombus, whereas hyperplasia of venous intima was 
the main factor 1-12 months after the surgery. The long-term patency rate after the operation was closely linked to venous atherosclerosis [8]. These factors significantly affected the early and late patency rate of the saphenous vein and further affected the safety and life quality of the patients [9]. Therefore, it is essential to determine how to improve the patency rate of the venous graft.

In 1996, the Swedish expert Souza's team initiated the NT technology, which retained part of the tissue surrounding the vein; the vein did not dilate manually after harvesting it. This reduced the damage to the vein's intimal, decreasing vascular smooth muscle cell activation, and protected against distensioninduced damage $[10,11]$. It also preserved intact vasa vasorum; this might present an excellent protective effect [12]. The clinical trials yielded encouraging results; the NT technique was safe and feasible. After 16 years of follow-up, the patency rate of venous grafts in the NT group was found to be comparable to that of the left internal mammary artery [13-15].

The NT technology is recommended as class lla in the 2018ESC/EACTS guide [16]. Previous studies on NT were mostly performed under cardiopulmonary bypass, and most of the vein grafts were individual coronary artery bypass grafts. However, there were few studies on off-pump bypass surgery with sequential venous grafts. Increasing clinical studies show that sequential graft is as safe and effective as a single graft [17-19]. It was not clear NT technology was used in the sequential saphenous vein grafting during off-pump coronary artery bypass surgery. The actual effect of NT technology in off-pump bypass surgery with sequential venous grafts needs to be further verified through further clinical trials. This study aimed to test the reliability of the NT technology in off-pump CABG in sequential venous grafts. It compared and analyzed the clinical data of the two groups pre and post-operation, as well as the incidence of graft occlusion and clinical events three months after the operation. Our hypothesis is that NT technique is safety and efficacy compared to the conventional technique in the sequential grafts during off-pump coronary artery bypass surgery.

\section{Methods}

\section{Study design}

This was a single-center, randomized controlled study comparing the difference between NT and the traditional vein harvested in the off-pump bypass surgery with sequential venous graft. Two hundred patients with at least three branches of coronary artery diseases, needing the left internal mammary artery and a sequential vein graft only were recruited. The enrollment of participants was determined by selecting random envelopes. The flow-chart and study design schedule are presented in Fig. 1.

\section{Participants}

This study recruited 200 patients with coronary heart disease who were to undergo off-pump coronary artery bypass grafting in cardiac surgery center China, from December 2018 to April 2020. 
The inclusion criteria were as follows: (a)Aged 18-80 years; (b) at least three-vessel coronary artery disease; (c) voluntarily joined the study and signed the informed consent. The exclusion criteria were: (a) Simultaneous operations (such as heart valve or lung or abdominal surgery); (b) emergent surgery; (c) ejection fraction $\leq 35 \%$; (d) complicated with the interventricular septal perforation and ventricular aneurysm; (e) redo CABG; (f) internal diameter of great saphenous vein $\leq 0.20 \mathrm{~cm}$, or varicose great saphenous vein, or venous tortuosity; (g) complicated with the severe malignant tumor or other serious systemic diseases; (h) severe renal insufficiency (creatinine > $200 \mu \mathrm{mol} / \mathrm{L}$ ); (i) dual antiplatelet taboo (j) severe peripheral vascular disease; $(k)$ allergic to the radiocontrast agent; (I)participating in other clinical trials at the same time.

\section{Randomization}

Participants will be randomly assigned (on a 1:1 ratio) to the NT and the CON groups with a random permuted block length of 4 patients per block, to ensure that trial groups at each block were balanced. Randomization was based on the computer-generated random digits table. All the random numbers were put in a sealed opaque envelope, sealed with a stapler, and locked in the file cabinet. Patients who satisfied all inclusion criteria and did not meet any of the exclusion criteria would open the cabinet to take out the envelope and draw lots. The specific scientific research secretary kept and facilitated the random drawing of lots. The study patients were blinded.

\section{Interventions}

\section{Surgical Techniques}

All patients were examined using bilateral great saphenous vein ultrasonography and marked before the operation. The patients received off-pump coronary artery bypass surgery with only one sequential venous graft. If hemodynamic instability or ventricular fibrillation occurred during off-pump bypass surgery, and the drug couldn't maintain stability, cardiopulmonary bypass would be established and surgery perform on-pump. Then the patient was excluded from the study. Leg wounds were sutured in three consecutive layers, and the leg wound was pressurized with an elastic bandage. The bandage was removed on the second-day post-operation and elastic socks worn for three months. If the trunk of the vein was very slender, or varicose or tortuous, it would be converted using the traditional technique, and the patient was excluded from this study.

\section{Nt Group}

The leg incision was cut longitudinally along the ultrasound mapping line made before the operation, and the trunk of the vein was exposed. When the trunk of the vein was dissociated, about $2 \mathrm{~mm}$ of the surrounding tissue was retained on both the left and right sides. The vein was not dilated after 
harvesting. It was marked with a signal pen to make preparations for distinguishing the course and direction of the anastomosed vein. After removal, the vein was stored in a mixture containing heparinized saline and papaverine hydrochloride. The vein was anastomosed proximally with the ascending aorta using a 6-0 polypropylene. The vein would be fully pre-dilated by aortic pressure and then examined for leakage. The sequential vein graft anastomoses were constructed end-to-side in the left and right crown systems using 7-0 or 8-0 polypropylene. The part of the vein graft with a longer distance between the two anastomoses was sutured to the heart's surface to prevent the vein from being twisted and kinked.

\section{Control Group}

The leg skin was cut longitudinally along the preoperative ultrasound marking line to expose the trunk and separate the visible branches. When the trunk of the vein dissociated, the surrounding tissue was not retained. The ankle vein was fixed using a small adaptor that connected to a $10 \mathrm{ml}$ syringe. The vein was dilated using a syringe filled with heparinized saline, checked for leakage, and placed in a mixture of heparinized saline and papaverine. Other operational processes were similar to the NT group.

\section{Medicine}

All patients were given anticoagulant therapy with low molecular weight heparin after admission, and the oral anticoagulants discontinued. Patients with underlying diseases (such as hypertension, diabetes, and hyperlipidemia) continued to take medicines until the day before the operation. Aspirin and statins were resumed 24 hours after the operation.

\section{Follow Up}

All patients underwent cardiac computed tomography angiography (CCTA) three months after the operation. The clinical events, recovery of the leg, and sternal wound complications were followed up.

\section{Outcome measures}

\section{Primary Outcome Measure}

The primary clinical end event was the occlusion rate of venous grafts three months after the operation. This was detected using cardiac computed tomography angiography (CCTA). Evaluation of graft failure: The number of failures was calculated by distal anastomosis. The graft and anastomotic failure were evaluated according to the FitzGibbon classification system [20]. FitzGibbon-A refered to a wide range of unobstructed grafts or less than $50 \%$ narrow grafts; FitzGibbon-B was a limited flow graft with a narrowing higher than $50 \%$. FitzGibbon-O refered to an occlusive graft without blood flow. In this study, FitzGibbon-A/B was used as patency and FitzGibbon-O as graft failure. The diseased graft was also regarded as a lesion if the lesion was located at the proximal /distal anastomosis site or the graft trunk. 
In this study, all patients in the two groups accepted sequential grafts, which had never been before. In order to know the effectiveness of the sequential grafts more early, CCTA detection was carried out in advance three months after operation. This was different from the primary outcome measure initially planned for one year after the surgery.

2. Secondary Outcome Measure

1. The composite clinical events: Major adverse cardiac and cerebrovascular events (MACCEs), including death from any cause, myocardial infarction, stroke, and repeat revascularization.

2. The leg wound complications.

Leg complications were defined as the wound not closing after 1 months, festering wound, or necrotic tissues present in the incision.

\section{Postoperative mortality}

The respiratory complications, myocardial infarction, stroke, acute renal failure, and atrial fibrillation in the post-operation were analyzed.

4. The average diameter of sequential grafts at three months

The saphenous vein expansion might have an effect on the long-term patency of the sequential grafts. Therefore, we used CCTA to compare the average diameter of the sequential graft of the two groups at 3 months after the surgery. There was no such plan at the beginning of the study in the protocol. The cardiac computed tomography angiography (CCTA) was used to measure the diameter of the sequential grafts in the proximal, middle, and distal segments, and then the average diameter of the grafts was calculated. The early expansion of sequential grafts was achieved by measuring the first 100 patients' mean diameter of sequential grafts, 3 months after the operation.

\section{Statistical Methods}

\section{Sample size calculation}

Using the difference test of the comparison of the two groups of rates, $a=0.05$, the degree of control is $90 \%$. The results of meta-analytic evidence indicate that the one-year patency rate of vein grafts with the traditional method is $85 \%$, and that of the no-touch way is expected to $95 \%$. According to the formula, the sample size of each group is 188 cases, and then increased by $15 \%$ in case of loss of follow-up, and the sample size of each group is 217 cases. Every patient has a sequential venous graft, with at least two anastomoses. According to the anastomotic ratio of 1 to 2 , and one anastomotic occlusion is an occurrence of the event, so the number of cases is about 200. 
SPSS 22.0 for Mac (IBM SPSS Statistics) was used for statistical analyses. Continuous variables were reported as the mean $+/-$ standard deviation or median (interquartile range) (IQR). Categorical variables were reported as the absolute frequency and as a percentage. The Student $t$-test was applied for continuous data with equal or unequal variances. The Mann-Whitney $U$ test was applied for continuous data that were not normally distributed. Pearson's $X^{2}$ and Fisher's exact tests were used for categorical data. Statistical significance was accepted at $p<0.05$.

\section{Results}

\section{Patients}

A total of 673 patients were recruited from December 2018 to April 2020 in Beijing Anzhen Hospital China. Finally, 200 patients were enrolled in the trial. A total of 100 patients were randomly assigned to the NT group and 100 patients to the CON group. A total of 187 patients (91 patients in the NT group and 96 patients in the CON group) received a follow-up survey. Thirteen patients (NT: 9, CON: 4) did not undergo the surgical technique assigned for non-adherence to the study design requirements. The flow of patients through the trial up to three months of follow-up is shown (Fig. 1). The groups were well matched in age, sex, body-mass index, smoking, left ventricular ejection fraction, previous medical history, and so on(Table 1). Intraoperative and postoperative data are shown in Table 2 and Table 3. 
Table 1

Characteristics of the Patients at Baseline

\begin{tabular}{|c|c|c|c|}
\hline Characteristic & $\begin{array}{l}\text { NT group } \\
(\mathrm{N}=91)\end{array}$ & $\begin{array}{l}\text { CON group } \\
(N=96)\end{array}$ & $P$-Value \\
\hline Age(year), mean \pm SD & $61.3 \pm 8.3$ & $61.2 \pm 7.6$ & 0.88 \\
\hline Male, n (\%) & $82(90.1)$ & $86(89.6)$ & 0.91 \\
\hline Body-mass index, $\mathrm{kg} / \mathrm{m}^{2}$, mean $\pm \mathrm{SD}$ & $26.2 \pm 3.1$ & $26.0 \pm 3.3$ & 0.60 \\
\hline Smoking, n (\%) & $45(49.5)$ & $58(60.4)$ & 0.13 \\
\hline Hypertension, n (\%) & $60(65.9)$ & $59(61.5)$ & 0.53 \\
\hline Diabetes mellitus, n (\%) & $40(44.0)$ & $44(45.8)$ & 0.80 \\
\hline Hyperlipidemia, n (\%) & $37(40.7)$ & $43(44.8)$ & 0.57 \\
\hline Peripheral vascular disease, $\mathrm{n}(\%)$ & $22(24.2)$ & $22(22.9)$ & 0.84 \\
\hline Previous stroke, n (\%) & $7(7.7)$ & $10(10.4)$ & 0.52 \\
\hline Previous myocardial infarction, n (\%) & $31(34.1)$ & $39(40.6)$ & 0.35 \\
\hline Previous $\mathrm{PCl}$, with or without stent, n (\%) & $14(15.4)$ & 13(13.5) & 0.72 \\
\hline \multicolumn{4}{|l|}{ Preoperative diagnosis } \\
\hline Stable angina, $\mathrm{n}(\%)$ & $30(33.0)$ & $37(38.5)$ & 0.43 \\
\hline Unstable angina, n (\%) & $59(64.8)$ & $57(59.4)$ & 0.44 \\
\hline NSTEMI, n (\%) & $2(2.2)$ & $2(2.1)$ & 1.00 \\
\hline \multicolumn{4}{|l|}{ NYHA classification, n (\%) } \\
\hline I & $2(2.2)$ & $3(3.1)$ & 1.00 \\
\hline ॥ & $59(64.8)$ & $68(70.8)$ & 0.38 \\
\hline III & $26(28.6)$ & $23(24.0)$ & 0.47 \\
\hline IV & 4.4 & $2(2.1)$ & 0.63 \\
\hline LVEF (\%), median (IQR) & $62(56,65)$ & $61(56,67)$ & 0.43 \\
\hline $\operatorname{LVEDD}(\mathrm{mm})$, mean \pm SD & $49.4 \pm 5.4$ & $48.6 \pm 5.4$ & 0.34 \\
\hline Euroscore II median (IQR) & $0.94(0.68,1.34)$ & $0.91(0.61,1.37)$ & 0.57 \\
\hline BNP(pg/ml), median (IQR) & $60(25,125)$ & $71(39,132)$ & 0.35 \\
\hline $\mathrm{TNI}(\mathrm{ng} / \mathrm{ml})$, median (IQR) & $0.01(0,0.06)$ & $0.01(0,0.03)$ & 0.09 \\
\hline $\mathrm{Cr}$ (umol/L), median (IQR) & $74.3(66.1,86.8)$ & $74.2(66.5,84.7)$ & 0.52 \\
\hline
\end{tabular}




\begin{tabular}{|llll|}
\hline Characteristic & $\begin{array}{l}\text { NT group } \\
(\mathbf{N}=91)\end{array}$ & $\begin{array}{l}\text { CON group } \\
(\mathbf{N}=96)\end{array}$ & P-Value \\
\hline AST(U/L), median (IQR) & $22(18,29)$ & $20(17,27)$ & 0.12 \\
\hline ALT(U/L), median (IQR) & $22(17,32)$ & $24(17,35)$ & 0.57 \\
\hline LDL-C(mmol/L), median (IQR) & $2.19(1.82,3.00)$ & $2.18(1.74,2.58)$ & 0.31 \\
\hline HGB(g/L), mean \pm SD & $130.0 \pm 14.6$ & $131.1 \pm 16.1$ & 0.82 \\
\hline HbA1c (\%), median (IQR) & $6.4(5.8,7.6)$ & $6.3(5.6,7.3)$ & 0.50 \\
\hline
\end{tabular}

Table 2

Surgical Characteristics

\begin{tabular}{|llll|}
\hline Variable & $\begin{array}{l}\text { NT Group } \\
(\mathbf{N}=91)\end{array}$ & $\begin{array}{l}\text { CON Group } \\
(\mathbf{N}=96)\end{array}$ & $P$-Value \\
\hline Number of grafts, $\mathrm{n}(\%)$ & & & \\
\hline In situ internal thoracic artery & $85(93.4)$ & $93(96.9)$ & 0.44 \\
\hline Double sequential & $69(75.8)$ & $68(70.8)$ & 0.44 \\
\hline Triple sequential & $22(24.2)$ & $28(29.2)$ & - \\
\hline Total number of distal anastomoses & 295 & 316 & - \\
\hline Left coronary territory & $197(66.8)$ & $206(66.0)$ & 0.68 \\
\hline Right coronary territory & $98(33.2)$ & $110(34.0)$ & - \\
\hline Graft flow, average, $\mathrm{n}(\%)$ & & & 0.56 \\
\hline 820 mL/min & $44(14.9)$ & $42(13.3)$ & 0.50 \\
\hline $20-39$ mL/min & $117(39.7)$ & $117(37.0)$ & 0.43 \\
\hline $40-59$ mL/min & $63(21.4)$ & $76(24.1)$ & 0.66 \\
\hline$\geq 60$ mL/min & $71(24.1)$ & $81(25.6)$ & 0.38 \\
\hline Left main disease, $\mathrm{n}$ (\%) & $28(30.8)$ & $24(25.0)$ & 0.25 \\
\hline Surgical duration(min) median (IQR) & $205(180-230)$ & $198(175-229)$ & \\
\hline
\end{tabular}


Table 3

Comparison of Early Results in Hospital

\begin{tabular}{|llll|}
\hline Variable & NT Group (N=91) & $\begin{array}{l}\text { CON Group } \\
(\mathbf{N}=96)\end{array}$ & P-Value \\
\hline Postoperative mortality, $\mathrm{n}(\%)$ & & & \\
\hline Bleeding reoperation & & $1(1.0)$ & 1.00 \\
\hline Myocardial infraction & $1(1.1)$ & $2(2.1)$ & 0.63 \\
\hline Acute renal failure & $4(4.4)$ & $4(4.2)$ & 0.73 \\
\hline Stroke & $2(2.2)$ & 0 & - \\
\hline Respiratory complication & 0 & $2(2.1)$ & 1.00 \\
\hline Atrial fibrillation & $2(2.2)$ & $23(24.0)$ & 0.70 \\
\hline IABP implantation & $24(26.4)$ & $2(2.1)$ & 0.63 \\
\hline Blood transfusion & $4(4.4)$ & $19(19.8)$ & 0.10 \\
\hline Postoperative duration, median (IQR) & $10(11.0)$ & & 0.64 \\
\hline Intubation time(h) & $16(13,20)$ & $16(13,19)$ & 0.64 \\
\hline ICU stay, (h) & $22(17,37)$ & $22(19,25)$ & 0.28 \\
\hline Hospital stay, (d) & $6(6,7)$ & $6(6,7)$ & 0.52 \\
\hline Postoperative bleeding (mI), median (IQR) & $400(250,600)$ & $400(250,700)$ & 0.60 \\
\hline Postoperative blood chemistry day 1 & & & 0.73 \\
\hline Hemoglobin (g/L), mean \pm SD & $103.58 \pm 16.71$ & $102.71 \pm 17.00$ & 0.73 \\
\hline BNP(pg/ml), median (IQR) & $301(209,501)$ & $280(192,433)$ & 0.37 \\
\hline TNI(ng/ml), median (IQR) & $0.40(0.19,0.82)$ & $0.37(0.20,0.76)$ & 0.80 \\
\hline Cr(umol/L),median (IQR) & $66.9(57.7,79.9)$ & $65.6(58.0,83.0)$ & 0.70 \\
\hline AST(U/L), median (IQR) & $22(16,31)$ & $21(15,25)$ & 0.16 \\
\hline ALT(U/L), median (IQR) & $17(12,26)$ & $16(11,24)$ & 0.26 \\
\hline HGB(g/L), median (IQR) & $107.0 \pm 17.8$ & $106.1 \pm 17.4$ & 0.73 \\
\hline IABP: intra-aortic balloon pump; ICU: intensive care unit & & \\
\hline
\end{tabular}

\section{Treatment}


Six patients in the NT group were converted to cardiopulmonary bypass because of hemodynamic instability. Two patients did not perform sequential venous graft owing to the absence of a suitable anastomosis site during the operation. A no-touch vein could not be harvest in one patient due to a slender vein. Therefore, these nine patients were excluded from the NT group. Likewise, three patients in the CON group were converted to cardiopulmonary bypass because of hemodynamic instability, and the sequential venous graft was not performed in one patient. These also were excluded. There were 85 $(93.4 \%)$ internal mammary arteries used in the NT group and $93(96.9 \%)$ in the CON group.

\section{Follow-up}

In the surgical arm, 165/187 (88.2\%)patients (NT: 91, CON:96) underwent a cardiac computed tomography angiography (CCTA). There was a $100 \%$ clinical follow-up (Fig. 1).

\section{Outcomes}

\section{Primary outcomes}

The total number of follow-up sequential vein anastomoses in the two groups was: NT (180/205(87.8\%)), and CON (194/221(87.8\%)) (Table4). The occlusion of sequential graft anastomoses at three months was not significantly different between the NT and the CON group: (NT: 9/180(5.0\%), CON: $5 / 194(2.6 \%), p=0.22$ ) (Fig. 2). In the NT group, seven sequential grafts occluded without blood flow from the anastomosis of the obtuse marginal branch to the posterior descending branch. One sequential graft occluded without blood flow starting from the beginning of the vein graft. In the CON group, one sequential graft occluded from the anastomosis of the obtuse marginal branch to the posterior descending branch. Two sequential grafts occluded from anastomosis of the diagonal and posterior left ventricular branch to the posterior descending branch. One sequential graft occluded without blood flow from the beginning of the vein graft. 
Main Outcomes and Adverse event at Three Months

\begin{tabular}{|llll|}
\hline Variable & $\begin{array}{l}\text { NT Group } \\
\mathbf{( N = 9 1 )}\end{array}$ & $\begin{array}{l}\text { CON Group } \\
(\mathbf{N}=96)\end{array}$ & P-Value \\
\hline Clinical outcome & & & \\
\hline Total number of follow-up distal anastomoses, $\mathrm{n}$ & 180 & 194 & \\
\hline Primary outcome: Vein occlusion, $\mathrm{n}(\%)$ & $9 / 180(5.0)$ & $5 / 194(2.6)$ & 0.22 \\
\hline Composite of MACCEs, $\mathrm{n}(\%)$ & $2(2.2)$ & $1(1.0)$ & 0.96 \\
\hline Death from any cause & $1(1.1)$ & 0 & 0.49 \\
\hline Myocardial infarction & 0 & 0 & - \\
\hline stroke & 0 & $1(1.0)$ & 1.00 \\
\hline Repeat revascularization & $1(1.1)$ & 0 & 0.49 \\
\hline Adverse event & & & 0.20 \\
\hline Leg wound complications, $\mathrm{n}$ (\%) & $8(8.8)$ & $4(4.2)$ & 1.00 \\
\hline Sternal wound complications, $\mathrm{n}$ (\%) & $1(1.1)$ & $2(2.1)$ & \\
\hline $\begin{array}{l}\text { SVG: Great Saphenous Vein; MACCEs: (death from any cause, myocardial infarction, repeat } \\
\text { revascularization, stroke) }\end{array}$ & & \\
\hline
\end{tabular}

\section{Secondary Outcomes}

There was no difference in the composite endpoint between the two groups: NT (2/91(2.2\%)) and CON $(1 / 96(1.0 \%))(p=0.96)$. However, one patient in the NT group died fifteen days after discharge due to respiratory failure; the patient was 76 years old, with a history of asthma. One patient in the NT group underwent $\mathrm{PCl}$ (percutaneous coronary intervention) before follow-up because of occlusion of the right graft and frequent angina pectoris. Three stents were implanted. In the CON group, one patient with cerebral infarction was hospitalized one month after discharge.

There were no differences in leg wound complications between the two groups: NT (8/91(8.8\%) and CON $(4 / 96(4.2 \%))(p=0.20)$ (Table 4).

\section{Postoperative Mortality}

There was a higher blood transfusion in group B than in group A: NT (10/91 (11.0\%)), and CON $(19 / 96(19.8 \%))(p=0.10)$ (Table 4$)$, but it was not statistically significant. There was no significant difference in postoperative bleeding (NT: 400 (250-600), CON: $400(250,700), p=0.60)$, and hemoglobin 
at the postoperative first day (NT: $103.58 \pm 16.71$, CON: $102.71 \pm 17.00, p=0.73$ ) between the two groups. There was no difference in the duration of surgery, intubation time, intensive care unit (ICU) stay time, and hospital stay between the two groups. There was also no difference observed in respiratory complications, myocardial infarction, stroke, acute renal failure, and atrial fibrillation in post-operation.

\section{The Average Diameter Of Sequential Grafts}

Among the first 100 patients, 2 in the NT group and 1 in the CON group failed the follow-up CTA examination. The diameters of sequential grafts measuring 48 and 49 were determined in the NT group and the CON group, respectively. The diameters of the proximal, middle, and distal segments of the sequential grafts were measured respectively. Since 4 cases of distal segment were occluded in the NT group, 44 cases of the distal diameter were measured. The CON group had a similar situation, so 48 cases were measured in the distal segment in the end. The detailed results were shown in Table 5.

Table 5

Comparison of average diameter of sequential grafts

\begin{tabular}{|llll|}
\hline Variable & $\begin{array}{l}\text { NT group }(\mathbf{N}= \\
\mathbf{4 8})\end{array}$ & $\begin{array}{l}\text { CON group }(\mathbf{N}= \\
\text { 49) }\end{array}$ & $P$-value \\
\hline Diameter (mm), mean \pm SD & & & \\
\hline Diameter of saphenous vein & $2.62 \pm 0.47$ & $2.71 \pm 0.78$ & 0.517 \\
\hline $\begin{array}{l}\text { Diameter of proximal segment of sequential } \\
\text { graft }\end{array}$ & $3.34 \pm 0.49$ & $3.47 \pm 0.64$ & 0.275 \\
\hline $\begin{array}{l}\text { Diameter of middle segment of sequential graft } \\
\text { Diameter of distal segment of sequential graft }\end{array}$ & $2.91 \pm 0.48$ & $3.17 \pm 0.53$ & 0.014 \\
\hline Average diameter of sequential graft & $2.68 \pm 0.48$ & $3.11 \pm 0.75$ & 0.002 \\
\hline
\end{tabular}

\section{Discussion}

This study aimed to explore whether the NT technique in patients undergoing off-pump coronary artery bypass grafting with the sequential saphenous vein grafting was safe and effective. To clarify the effect of NT technique in sequential grafts, the clinical data of the two groups were compared and analyzed during and post-operatively, as well as the incidence of graft occlusion and clinical events 3-months postoperation. The results showed that the NT technique is safety and efficacy compared to the conventional vein grafting technique in the sequential grafts during off-pump coronary artery bypass surgery.

Studies in related fields demonstrated that the NT technology is safe and feasible, however, the leg wound complications did not present the same as in the NT group. Likewise, our study suggested that the leg wound complications in the NT group were slightly more than those in the CON group. In previous studies, a drainage tube was routinely placed after an operation on the leg wound [21]. However, no such 
drainage tube was used in our study, which may explain the high number of wound complications in the NT group.

In this study, there were more incidences of venous graft occlusion in the NT group; although the difference, between the two groups, was not significant (Fig. 2), attention should be paid to it. Studies show that there is no significant difference in the patency rate of the venous grafts between the no-touch and the conventional vein grafts at the early stages, and there was a trend of lower occlusion rate in the no-touch group. However, the results of this study were slightly different probably due to the following factor: Most of the occlusion of the grafts occurred near the posterior descending branch in the NT group whereas this study used a sequential graft, which could reach the posterior descending branch from the farthest point of the aorta. The graft was relatively long, and the graft was not manually dilated. The length of the graft may have been too long and the distal posterior descending branch couldn't be fully expanded by the aortic blood pressure. Moreover, the vein of the Asian population differs from that of the Swedish; the diameter of the vein is smaller, and it was bound by perivascular tissue, which made the distal end of the vein grafting difficult to expand.

Most of the previous studies on NT technology were retrospective, whereas prospective and randomized controlled studies were mainly from the Swedish Souza team. Most studies were performed under cardiopulmonary bypass, or the saphenous vein was individually graft. This study performed NT technology all in off-pump CABG with the sequential grafts. In on-pump surgery, the empty and flaccid heart hampered the correct estimation of graft configurations in a full-beating heart. The use of off-pump CABG could prevent these challenges; off-pump procedures appeared to be associated with a reduced risk of early morbidities, such as a stroke, and fewer transfusion [22-24]. There was only one saphenous vein graft in the present study, and they were all sequential grafts, which per graft had at least two anastomoses. There was no difference between the sequential graft and single graft in MACCEs events in multiple previous studies. One advantage of the sequential graft is using a minimal length of SVG. There is also less tendency for the graft to kink because of the perivascular tissue in the NT group. However, failure of a single sequential conduit jeopardizes all of the anastomoses along that graft segment.

As in the Souza trial, ultrasound was used to locate the saphenous vein in all patients before operation. The size of the great saphenous vein in Asian people is different from that in European people such as the Swedish; it is often thin in the Asian population. The pre-experiment experience showed that when the ultrasound reported the vein as thin, it would be challenging to succeed in harvesting a no-touch vein because of its fineness, even breaking the trunk of the vein. Preoperative ultrasound can reduce unnecessary incisions and save operation time.

One of the characteristics of the NT technology was that the vein was not manually expanded after harvesting. The expansion of the vein graft depended entirely on the blood pressure of the aorta. In this case, the degree of postoperative expansion of the graft obtained using NT may be weaker than that of the conventional group. Therefore, CCTA was used to compare the average diameter of the sequential graft of the two groups 3 months after surgery. The results indicate that the average diameter of veins in 
the NT group is significantly less than that in the conventional group (Fig. 3). This suggested that the NT technology reduced the damage caused by vein expansion while ensuring the safety and effectiveness of the surgery. This milder vein expansion may have a protective effect on the long-term patency of the sequential grafts.

There were limitations in this study: The study was a single-center research; The patients in the group were mainly from the north of China, which may present a bias in the results. A multicenter, large sample, prospective randomized controlled study may be carried out in the future, which can provide more definitive evidence for the effect of NT technology; the primary endpoint event was the occlusion rate of the venous graft three months after the operation. The Souza team's study conducted 72 cases 8.5 years after the surgery and 27 cases 16 years in each group. The longer the follow-up time, the more significant difference appeared between the two groups. Therefore, this study will continue to follow up the patients for one, five, ten years, or even longer; finally, samples sizes were determined for the variables at the cardiac computed tomography follow-up one year after the surgery and not for the end points that were the focus of this study. More extensive studies with long-term follow-up with clinical endpoints are warranted.

\section{Conclusions}

The early clinical results suggest that the NT technique is safety and efficacy compared to the conventional vein grafting technique in the sequential saphenous vein grafting during off-pump coronary artery bypass surgery. The sequential grafts early expansion in the NT technique is not as distinct as the conventional technique, which may have a long-term protective effect on the grafts. These findings add to the accumulating evidence that no-touch is an alternative manner in sequential saphenous vein grafting during off-pump coronary artery bypass surgery. Large-scale prospective randomized controlled studies currently underway may be able to more fully prove the clinical effects of NT technology in the future.

\section{Abbreviations}

CABG

Coronary artery bypass grafting; NT:No-touch saphenous vein graft harvesting; CON:Conventional saphenous vein graft harvesting;

CCTA

Cardiac computed tomography angiography; SVG:Saphenous vein graft; MACCE:Major adverse cardiac and cerebrovascular events; ICU:Intensive care unit; PCl:Percutaneous coronary intervention; IABP:Intraaortic balloon pump; IQR:Interquartile range; NSTEMI:Non ST segment elevation myocardial infarction; NYHA:New York Heart Association; LVEF:Left ventricular ejection fraction; LVEDD:Left ventricular end diastolic; BNP:B-type natriuretic peptide; Tnl:Troponin I; Cr:Creatinine; AST:Aspartate aminotransferase; ALT:Alanine aminotransferase; LDL-C:Low density lipoprotein-cholesterol; HGB:Hemoglobin; $\mathrm{HbA1c:Glycosylated} \mathrm{hemoglobin.}$ 


\section{Declarations}

\section{Ethics Approval and consent to participate}

The Ethics Committee of Beijing Anzhen Hospital and Capital Medical University (Approval Numbers:2018036X) approved the study. Each patient signed informed consent before enrollment.

\section{Consent for Publication}

Not applicable

\section{Acknowledgements}

We thank the funding of the Beijing Hospital Authority Project, and all the patients who participated in the trial.

\section{Funding}

This work was supported by funding of the Beijing Hospital Authority Project (PX2018027). The funding units did not participate in the design of the study and the implementation of related measures.

\section{Availability of data and materials}

The datasets used and/or analyzed during the current study are available from the corresponding author on reasonable request.

\section{Conflicts of interest}

It should be recognized that none of the authors have any financial or scientific conflicts of interest with regard to the research described in this manuscript.

\section{Authors' contributions】}

DR and ZJB were responsible for the design, supervision of the study, and revision of the manuscript. HXJ drafted the manuscript. HZH and ZK did the trial registration and manuscript revision. LY, XSJ and SBR designed a statistical plan. ZJB and LTS participated in the revision of the manuscript and the coordination of the study. William AW and ZY participated in data acquisition. All authors read and agreed to the final manuscript.

\section{References}

1. Cavalcante R, Sotomi Y, Lee CW, Ahn JM, Farooq V, Tateishi H, Tenekecioglu E, Zeng Y, Suwannasom $\mathrm{P}$, Collet $\mathrm{C}$ et al: Outcomes After Percutaneous Coronary Intervention or Bypass Surgery in Patients With Unprotected Left Main Disease. J Am Coll Cardiol 2016, 68(10):999-1009. 
2. Chang M, Ahn JM, Lee CW, Cavalcante R, Sotomi Y, Onuma Y, Tenekecioglu E, Han M, Park DW, Kang SJ et al: Long-Term Mortality After Coronary Revascularization in Nondiabetic Patients With Multivessel Disease. J Am Coll Cardiol 2016, 68(1):29-36.

3. Head SJ, Milojevic M, Taggart DP, Puskas JD: Current Practice of State-of-the-Art Surgical Coronary Revascularization. Circulation 2017, 136(14):1331-1345.

4. ElBardissi AW, Aranki SF, Sheng S, O'Brien SM, Greenberg CC, Gammie JS: Trends in isolated coronary artery bypass grafting: an analysis of the Society of Thoracic Surgeons adult cardiac surgery database. J Thorac Cardiovasc Surg 2012, 143(2):273-281.

5. Zhao DX, Leacche M, Balaguer JM, Boudoulas KD, Damp JA, Greelish JP, Byrne JG, Writing Group of the Cardiac Surgery CA, Interventional Cardiology Groups at the Vanderbilt H, Vascular I et al: Routine intraoperative completion angiography after coronary artery bypass grafting and 1-stop hybrid revascularization results from a fully integrated hybrid catheterization laboratory/operating room. $J$ Am Coll Cardiol 2009, 53(3):232-241.

6. Hlatky MA, Boothroyd DB, Reitz BA, Shilane DA, Baker LC, Go AS: Adoption and effectiveness of internal mammary artery grafting in coronary artery bypass surgery among Medicare beneficiaries. $J$ Am Coll Cardio/ 2014, 63(1):33-39.

7. Hess CN, Lopes RD, Gibson CM, Hager R, Wojdyla DM, Englum BR, Mack MJ, Califf RM, Kouchoukos NT, Peterson ED et al: Saphenous vein graft failure after coronary artery bypass surgery: insights from PREVENT IV. Circulation 2014, 130(17):1445-1451.

8. Dashwood MR, Tsui JC: 'No-touch' saphenous vein harvesting improves graft performance in patients undergoing coronary artery bypass surgery: A journey from bedside to bench. Vascular Pharmacology 2013, 58(3):240-250.

9. Samano N, Bodin L, Karlsson J, Geijer H, Arbeus M, Souza D: Graft patency is associated with higher health-related quality of life after coronary artery bypass surgery. Interact Cardiovasc Thorac Surg 2017, 24(3):388-394.

10. Dashwood MR, Savage K, Tsui JC, Dooley A, Shaw SG, Fernandez Alfonso MS, Bodin L, Souza DS: Retaining perivascular tissue of human saphenous vein grafts protects against surgical and distension-induced damage and preserves endothelial nitric oxide synthase and nitric oxide synthase activity. J Thorac Cardiovasc Surg 2009, 138(2):334-340.

11. Verma S, Lovren F, Pan Y, Yanagawa B, Deb S, Karkhanis R, Quan A, Teoh H, Feder-Elituv R, Moussa F et al: Pedicled no-touch saphenous vein graft harvest limits vascular smooth muscle cell activation: the PATENT saphenous vein graft study. Eur J Cardiothorac Surg 2014, 45(4):717-725.

12. Dreifaldt M, Souza DS, Loesch A, Muddle JR, Karlsson MG, Filbey D, Bodin L, Norgren L, Dashwood MR: The "no-touch" harvesting technique for vein grafts in coronary artery bypass surgery preserves an intact vasa vasorum. $J$ Thorac Cardiovasc Surg 2011, 141(1):145-150.

13. Souza DS, Johansson B, Bojo L, Karlsson R, Geijer H, Filbey D, Bodin L, Arbeus M, Dashwood MR: Harvesting the saphenous vein with surrounding tissue for CABG provides long-term graft patency 
comparable to the left internal thoracic artery: results of a randomized longitudinal trial. $J$ Thorac Cardiovasc Surg 2006, 132(2):373-378.

14. Johansson BL, Souza DS, Bodin L, Filbey D, Bojo L: No touch vein harvesting technique for CABG improves the long-term clinical outcome. Scand Cardiovasc J 2009, 43(1):63-68.

15. Samano N, Geijer H, Liden M, Fremes S, Bodin L, Souza D: The no-touch saphenous vein for coronary artery bypass grafting maintains a patency, after 16 years, comparable to the left internal thoracic artery: A randomized trial. J Thorac Cardiovasc Surg 2015, 150(4):880-888.

16. Neumann FJ, Sousa-Uva M, Ahlsson A, Alfonso F, Banning AP, Benedetto U, Byrne RA, Collet JP, Falk V, Head SJ et al: 2018 ESC/EACTS Guidelines on myocardial revascularization. Eur Heart J 2019, 40(2):87-165.

17. Al-Ruzzeh S, George S, Bustami M, Nakamura K, Khan S, Yacoub M, Amrani M: The early clinical and angiographic outcome of sequential coronary artery bypass grafting with the off-pump technique. $J$ Thorac Cardiovasc Surg 2002, 123(3):525-530.

18. Kim HJ, Lee TY, Kim JB, Cho WC, Jung SH, Chung CH, Lee JW, Choo SJ: The impact of sequential versus single anastomoses on flow characteristics and mid-term patency of saphenous vein grafts in coronary bypass grafting. J Thorac Cardiovasc Surg 2011, 141(3):750-754.

19. Park SJ, Kim HJ, Kim JB, Jung SH, Choo SJ, Lee JW, Chung CH: Sequential Versus Individual Saphenous Vein Grafting During Coronary Arterial Bypass Surgery. Ann Thorac Surg 2019.

20. Fitzgibbon GM, Kafka HP, Leach AJ, Keon WJ, Hooper GD, Burton JR: Coronary bypass graft fate and patient outcome: Angiographic follow-up of 5,065 grafts related to survival and reoperation in 1,388 patients during 25 years. Journal of the American College of Cardiology 1996, 28(3):616-626.

21. Kim YH, Oh HC, Choi JW, Hwang HY, Kim KB: No-Touch Saphenous Vein Harvesting May Improve Further the Patency of Saphenous Vein Composite Grafts: Early Outcomes and 1-Year Angiographic Results. Ann Thorac Surg 2017, 103(5):1489-1497.

22. Lamy A, Devereaux PJ, Prabhakaran D, Taggart DP, Yusuf S: Off-Pump or On-Pump Coronary-Artery Bypass Grafting at 30 Days. New England Journal of Medicine 2012, 366(16):1489-1497.

23. Lamy A, Devereaux PJ, Prabhakaran D, Taggart DP, Hu S, Paolasso E, Straka Z, Piegas LS, Akar AR, Jain AR et al: Effects of off-pump and on-pump coronary-artery bypass grafting at 1 year. $\mathrm{N} \mathrm{Eng/} J$ Med 2013, 368(13):1179-1188.

24. Lamy A, Devereaux PJ, Prabhakaran D, Taggart DP, Hu S, Straka Z, Piegas LS, Avezum A, Akar AR, Lanas Zanetti $F$ et al: Five-Year Outcomes after Off-Pump or On-Pump Coronary-Artery Bypass Grafting. N Engl J Med 2016, 375(24):2359-2368.

\section{Figures}




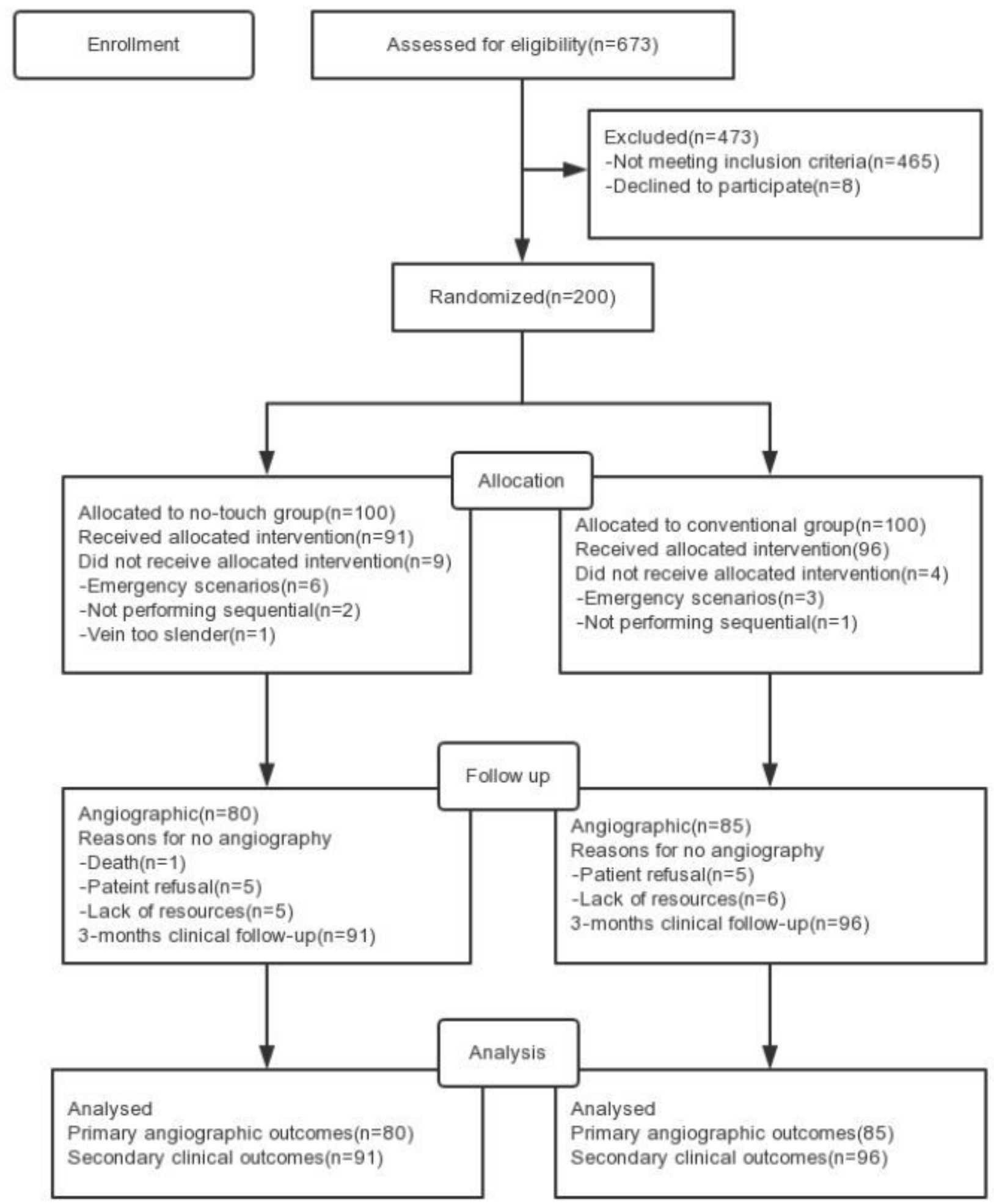

\section{Figure 1}

\section{Summary flow diagram of enrolled patients}




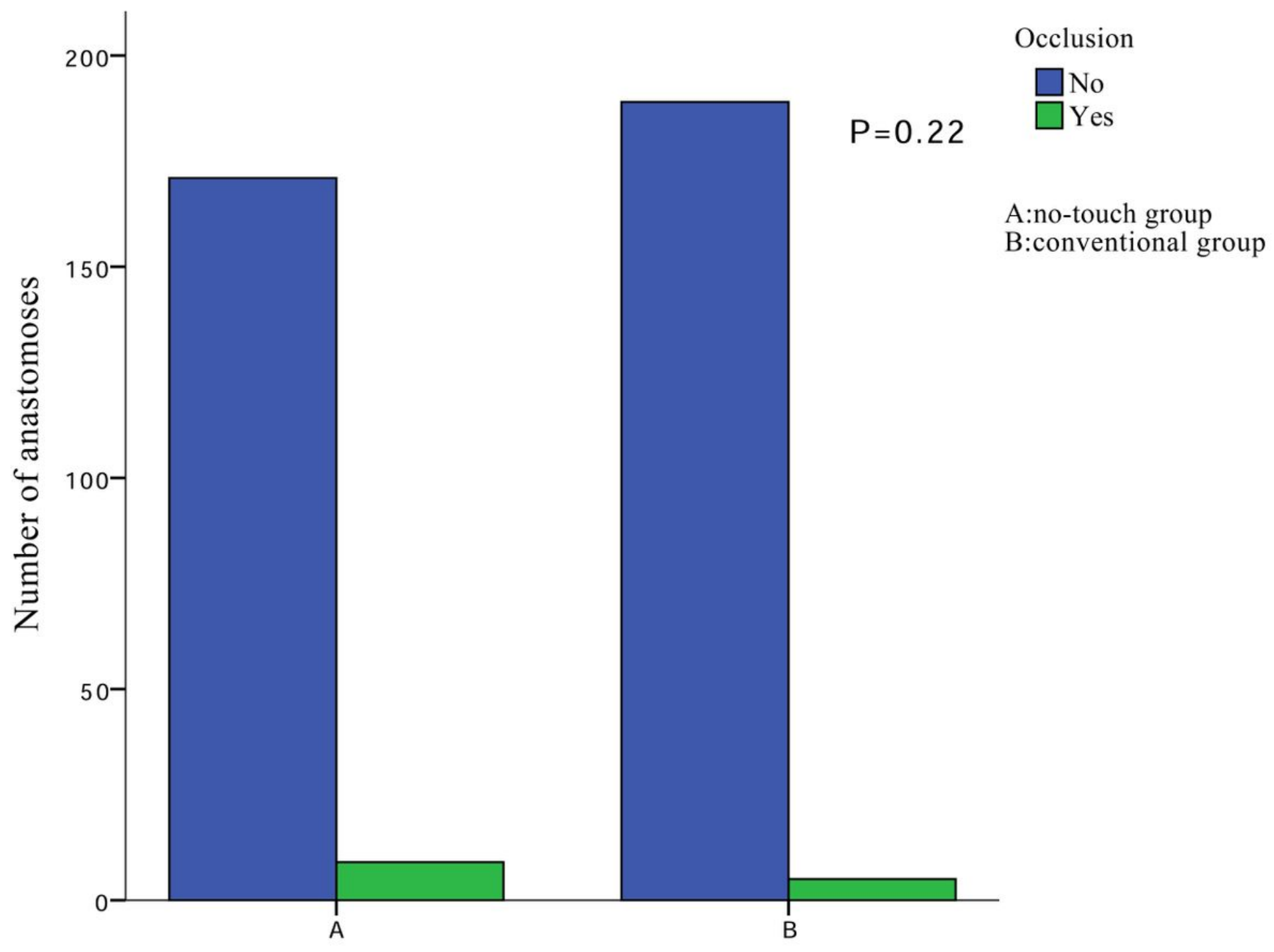

Fig2. Comparison of patency rate of sequential venous grafts

Figure 2

Comparison of patency rate of sequencial venous graft 


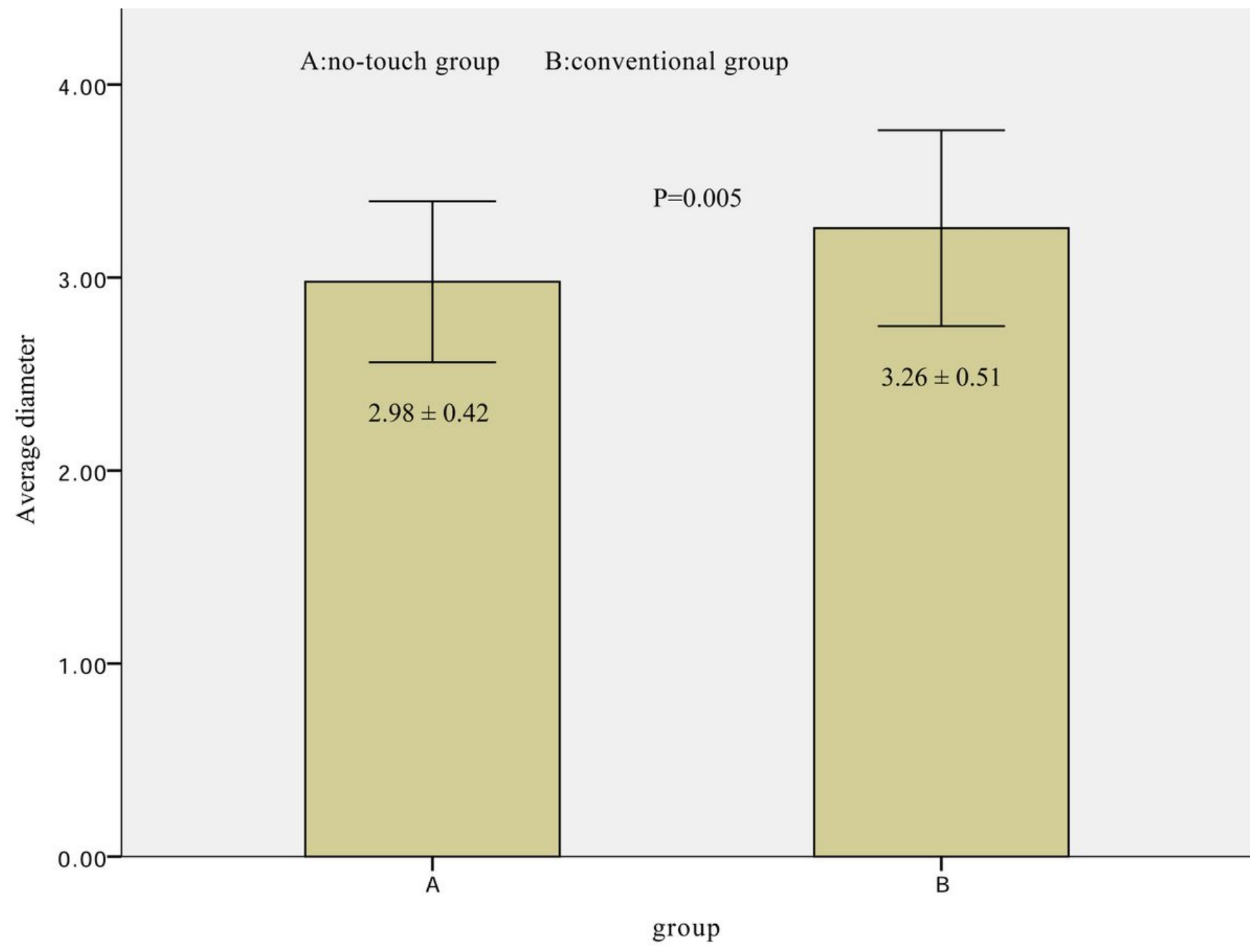

Fig3. Comparison of average diameter of sequential grafts

Figure 3

Comparison of average diameter of sequential grafts

\section{Supplementary Files}

This is a list of supplementary files associated with this preprint. Click to download.

- CONSORT2010Checklist.doc

- Protocol.docx 